Research Article

\title{
Study on sustained release effect of Sertraline hydrochloride with Ghee complex
} Tilotma Sahu", Abhishek kumar, Chanchal Deep Kaur

Shri Rawatpura Sarkar Institute of Pharmacy, Kumhari,Durg, Chhattisgarh, India

Objective: The objective of the study was to increase the bioavailability of drug by preparing complex of Sertraline $\mathrm{HCl}$ with ghee. Materials and methods: Dissolution study was done by using paddle apparatus USP type 2 and permeation studies were performed by everted intestinal method. The different ratios of complexes were prepared by solvent evaporation method and evaluated. The complexes of Sertraline HCl: native ghee complex (1:1 to 1:5). Results: The permeation of pure drug was found to be $86 \%$ at 1 hour. In complex ratio drug: ghee 1:1, it showed $42.55 \%$ drug permeation at 15 minutes, $78.14 \%$ at 45 minutes. In 1:2 (drug: ghee complex) it shows $46.93 \%$ drug permeation at 15 minutes, $85.53 \%$ at 45 minutes. In drug: ghee (1:3) \% drug permeation at 15 minutes it was $50.26 \%$ and increases to $92.23 \%$ at 45 minutes. In complex 1:4(drug :ghee) at 15 minutes the $\%$ drug release was $55.41 \%$ and increasingly it goes to $95.22 \%$ at 45 minutes .In drug: ghee (1:5) \% drug release at 15 minutes it was $60.12 \%$ and 98.25\% at 45 minutes. In drug: oxidized ghee (1:1) the \% drug permeation was $40.83 \%$ at 15 minutes which increases to $76.25 \%$ at 45 minutes. In drug: ghee (1:2) $42.58 \%$ drug permeates at 15 minutes, $89.88 \%$ at 45 minutes. Again by increasing the amount of ghee in ratio (1:3) it gives 48.95\% release at 15 minutes than 90.15 at 45 minutes, in (1:5) drug: ghee complex shows $59.87 \%$ at 15 minutes and at 45 minutes the drug complex permeates $96.16 \%$ drug. Thus the prepared complexes effectively increased the drug permeation. In dissolution study of Sertraline $\mathrm{HCl}$, the percent drug release of pure Sertraline $\mathrm{HCl}$ was $35.83 \%$ at 15 minutes and $48.29 \%$ at 45 minutes. Again in complex ratios of $1: 1$ to $1: 5$ at 15 minutes was $25.09 \%, 19.23 \% 14.55 \% 10.89 \%$ and $6.95 \%$ respectively, at 45 minutes the percent drug release of drug: ghee complex1:1 to 1:5 was found to be $46.25 \%, 39.88 \% 31.89 \%, 25.78 \%, 21.99 \%$ drug release respectively. Conclusion: From the above studies we found that increasing the amount of ghee in complexes there is decrease in dissolution of drugs and increasing in permeation. Thus the prepared complexes effectively increased the drug permeation.

Keywords: Permeation, dissolution, ghee, bioavailability, Sertraline

\section{Introduction}

Drugs with low water solubility are predisposed to poor and variable oral bioavailability and, therefore, to variability in clinical response, that might be overcome through an appropriate formulation of the drug (Censi and Martino, 2015). Permeability and solubility are key underlying parameters for controlling drug absorption (Kotamkar and Sakarkar, 2014). Novel drug delivery technologies developed in recent years for solubility enhancement of insoluble drugs are size reduction

\footnotetext{
*Address for Corresponding Author:

Tilotma Sahu,

Shri Rawatpura Sarkar Institute of Pharmacy, Kumhari, Durg, Chhattisgarh, India

Email: tilu06sahu@gmail.com
}

technologies; lipid based delivery system, micelles technologies. Solid Dispersion Technique and various types of solid dispersion systems have also been used (Kansara et al., 2015). Developed and developing countries move towards a combination therapy used for the treatment of diseases requiring long-term therapy. Further, low dose combination of two different drugs decreases the clinical and metabolic side effects that occur with a maximal dosage of an individual component of the combined tablet and so dose of one component can be decreased (Salih, 2015). Oral sustained release dosage forms were the most commonly formulated and offer highest interesting in the area of novel drug delivery systems. Prolonging the gastric retention is desirable for achieving the therapeutic benefit of drugs that are absorbed in the stomach and small

DOI: https://doi.org/10.31024/apj.2018.3.3.4

2456-1436/Copyright (C) 2018, N.S. Memorial Scientific Research and Education Society. This is an open access article under the CC BYNC-ND license (http://creativecommons.org/licenses/by-nc-nd/4.0/). 
intestine. Sustain release and gastric retention mechanisms had the benefit of such drugs by improving their bioavailability, therapeutic efficacy and reduction of dose.

Sertraline $\mathrm{HCl}$ - BCS class II drug is a selective serotonin reuptake inhibitor is indicated for the treatment of depression and anxiety disorders, including obsessive-compulsive disorder, panic disorder and post-traumatic stress disorder. It is considered suitable for the treatment of depressive symptoms in elderly patients, including those with Alzheimer's disease (AD), as it has minimal anti-cholinergic activity and is essentially devoid of cardiovascular effects. Furthermore, Sertraline $\mathrm{HCl}$ may be useful in the management of other behavioural problems experienced by $\mathrm{AD}$ patients that are likely mediated by the serotonergic system, such as anxiety, irritability and aggression (Hussein et al., 2014).

Ghee commonly called "Gritha" in Sanskrit, has been utilized for thousands of years in Ayurveda as part of diet. According to Ayurveda, ghee promotes longevity and protects body from various diseases. It increases digestive fire and improves absorption, nourishes, improves memory and strengthens the brain and nervous system, lubricates the connective tissues, thereby rendering the body more flexible. In India ghee was used as a vehicle in many Ayurveda Medicinal preparations. Ghee cools the body and prevents overheat. Ghee makes internal body organs smooth and soft and also increases secretion of internal juices, which are diminished by aging. Ghee improves intelligence and intellect. Ghee is also better in wound healing. Recently, many studies have proved that ghee is good for health (Nirmala et al., 2016).

Our objective is that Poor solubility and permeability of slightly soluble drug "Sertraline hydrochloride", face a problem of low bioavailability (absolute bioavailability 44\%) as its dissolution and permeation are the rate limiting factors, so it becomes a requirement to improve dissolution and permeability of Sertraline Hydrochloride by preparing complexes with native cow ghee and oxidized cow ghee.

\section{Materials and methods}

\section{Materials}

Sertraline $\mathrm{HCl}$ was gifted from matrix laboratory; Hyderabad. Cow ghee was purchased from Dharma Peth Nagpur. Some other chemicals like methanol, sodium acetate trihydrate, glacial acetic acid, Sodium chloride, Potassium chloride, Magnesium chloride calcium chloride, sodium bicarbonate, sodium hydrogen phosphate, Sodium di-hydrogen phosphate potassium di-hydrogen orthophosphate were purchased from chemical shop, Raipur (C.G).

Fresh slaughtered cockerel intestine bought from the nearest slaughter residence which was kept in tyrode's solution at $25^{\circ} \mathrm{C}$, until similarly use. gadget and assembly for everted intestine become assembled the use of reservoir (made from glass and plastic field) having capacity of $250 \mathrm{ml}$ with controlling valve for tracking the glide rate of solution undergo the pipe to the assembly, the assembly was prepared in glass container in which inlet and outlet have been made by clamping pipe in both aspect of inverted intestine, one is hooked up to reservoir as inlet and every other pipe are used as outlet. Electric meeting are used for oxygen deliver to the tissue via the aerator. A shimadzu1700 UV seen spectrophotometer with $1 \mathrm{~cm}$ matched silica cells turned into used for spectrophotometric analysis.

\section{Preparation of Standard Stock Solution}

Stock solution were prepared by dissolving $50 \mathrm{mg}$ of sertrline $\mathrm{HCl}$ in methanol which was taken in volumetric flask $(100 \mathrm{ml})$ then sonicated for $15 \mathrm{~min}$ and diluted up to $100 \mathrm{ml}$ with the same solvent so as to get the concentration of $100 \mu \mathrm{g} / \mathrm{ml}$. This stock solution is used for making dilutions for calibration curve (Ratnia et a., 2015).

\section{Determination of $\lambda_{\text {max }}$}

The standard solution of sertrline $\mathrm{HCl}$ scanned at different concentration in the range of $200-400 \mathrm{~nm}$ and the $\lambda$ max was determined.

Preparation of Calibration Curve: Suitable aliquots have been pipette out from preferred stock solution into the series of $10 \mathrm{ml}$ volumetric flask and the volume was made up to the mark with methanol to get concentration of 1-10 $\mu \mathrm{g} / \mathrm{ml}$ of Sertraline $\mathrm{HCl}$. Solutions of different concentrations for were analysed at their respective wavelengths and absorbance's were recorded (Ratnia et al., 2015).

\section{Preparation of binary complexes at different ratio}

Complexes of drug with native and oxidized have been prepared through solvent evaporation approach. Fusion admixture of Sertraline $\mathrm{HCl}$ : ghee changed into organized by way of melting the ghee in a beaker over a water bathtub maintained at $65-70^{\circ} \mathrm{c}$ temperature. To the molten ghee an equal quantity of drug had been brought, and uniformly dispersed by continuous stirring to put together binary combination. The ration $1: 1$ to at least $1: 5 \mathrm{w} / \mathrm{w}$ ratios become decided on to maximise the likelihood of observing any interplay the fussed aggregate turned into homogenized and allow to cool slowly to room temperature with stirring. The binary combination was stored in amber shade glass bottles. Native ghee was oxidized via heating it in an electric powered chrome steel oven at $120^{\circ} \mathrm{c}$ for 50 hours. 
The complexes in same ratios were organized by the usage of oxidized ghee also.

\section{In-vitro drug release study}

The paddle apparatus USP type 2 was adopted in this study. The release medium consisted of $900 \mathrm{ml}$ of phosphate buffer $(6.4 \mathrm{pH})$. A known quantity from each batch of the drug were placed in chamber of the release apparatus and agitated at $60 \mathrm{rpm}$. The temperature of the dissolution medium was controlled at $37 \pm 0.5$ C. $5 \mathrm{ml}$ of the dissolution medium were sampled at appropriate intervals (15 min.), and fresh dissolution medium (6.4 $\mathrm{PH}$ phosphate buffer) was simultaneously replenished in the apparatus to maintain a constant volume and absorbance was determined at a respective wavelength using UV spectrophotometer (Hussein et al., 2014).

\section{Ex-vivo intestinal permeation study}

\section{Experiments using everted intestine method:}

Six setup of pure drug sample and complexes drug: ghee was prepared and there quantity was taken according to their therapeutic dose respectively. The fresh cock intestine was bought from the slaughter house. A $10 \mathrm{~cm}$ of intestine was everted and the inlet and outlet were made by clamping two pipes in both side of everted intestine in which one is connected to reservoir as inlet and another pipe are used as outlet. This everted intestinal setup was dipped in beaker containing drug and $6.4 \mathrm{pH}$ phosphate buffer. From the reservoir $7.4 \mathrm{pH}$ phosphate buffer was supplied, about $15 \mathrm{ml}$ volume was filled inside the everted intestine. After each 15 minutes interval the filled solution inside the intestine was taken out (about $5 \mathrm{ml}$ ), the flow rates were controlled by controlling valve having in reservoir pipe. Again makeup the volume with $7.4 \mathrm{pH}$ phosphate buffer up to $15 \mathrm{ml}$ inside the intestine. The procedure was followed for 135 minutes and intermittent samples were collected. After suitable dilutions by UV spectrophotometer the absorbance were taken at suitable wavelength. Concentration of drug in each sample was determined by regression equation (Kale et al., 2007).

\section{Statistical analysis}

The experiment was performed in triplicate. Results were expressed as mean \pm standard deviation.

\section{Results and discussion}

\section{UV Spectroscopy}

The absorption maximum of Sertraline $\mathrm{HCl}$ in methanolic solution was found to be $220 \mathrm{~nm}$ against aqueous methanol used as blank.

In the linearity study, regression equation and correlation coefficient for Sertraline $\mathrm{HCl}$ (figure 1) was found to be:

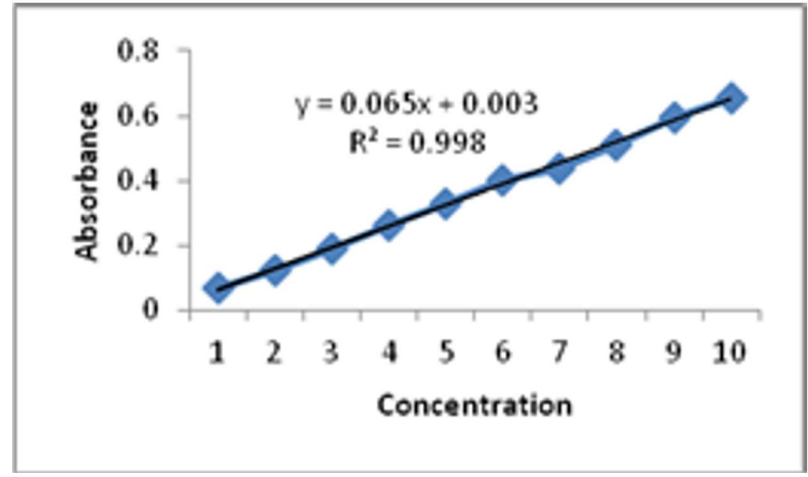

Figure 1. Calibration Curve of Sertraline $\mathrm{HCl}$

\section{In-vitro release study}

The release study of Control (pure Sertraline $\mathrm{HCl}$ ) and their Complex with native ghee at different ratio $(1: 1,1: 2,1: 3$, $1: 4$ and 1:5) were studied and calculated for drug releases then graph were plotted between \% Drug Release Vs Time.

In the experiments (figure 2), it was observed that Sertraline $\mathrm{HCl}$ control drug shows that at 15 minutes the \% drug release was found to be $35.83 \%$, and $85.03 \%$ at 90 minutes. When prepare a complex with ghee (1:1), (1:2), (1:3), (1:4), $(1: 5)$ it shows decreased \% drug release as compare to control drug which was $25.09 \%, 19.23 \%, 14.55 \%, 10.89 \%$, $6.95 \%$ at 15 minutes respectively and $75.95 \%, 69.26 \%$, $62.47 \%, 53.87 \%, 45.95 \%$ at 90 minutes respectively.

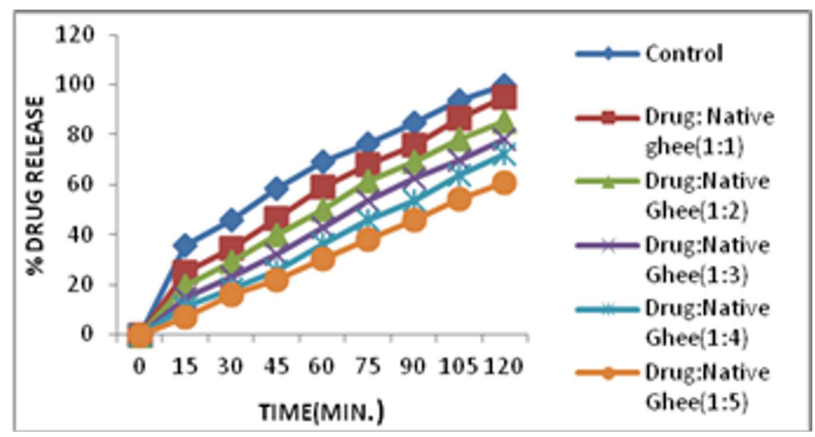

Figure 2. Dissolution Study of Drug: Native Cow Ghee

The complexion of Sertraline $\mathrm{HCl}$ with oxidized ghee were studied and percent drug release were calculated where the result was found that shown in (figure 3) at 15 minutes the percent drug release of control drug, drug: oxidized cow ghee $(1: 1),(1: 2),(1: 3), 1: 4), 1: 5)$ was $35.83 \%, 26.87 \%$, $20.16 \%, 15.56 \%, 11.23 \%$ and $7.87 \%$ respectively. And at 90 minutes it was found $85.03 \%, 76.89 \%$, and $70.18 \%$ $63.76 \% 55.78 \%$ and $47.25 \%$ percent drug release respectively which shows that by increasing the ration of ghee decreases the release of drug from dissolution medium. $y=0.065 x+0.003, R^{2}=0.998$. 


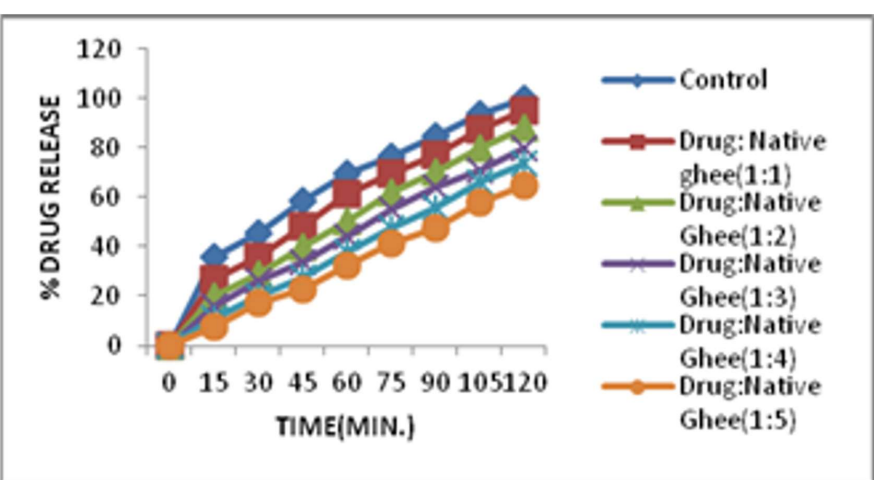

Figure 3. Dissolution Study of Drug: Oxidized Cow Ghee

\section{Permeation study}

The permeation of Sertraline $\mathrm{HCl}$ and there complexes at different ratio was studied and calculated for $\%$ drug permeation with respect of time. The Drug: Ghee complexes 1:1, 1:2, 1:3, 1:4, 1:5 were prepared for the permeation study.

Permeation study of Sertraline $\mathrm{HCl}$ (figure 4) was observed that control drug shows permeability as $39.87 \%$ in 15 minutes, $72.99 \%$ at 45 minutes and it completely permeates drug within 90 minutes. In complexation ratios (drug: native cow ghee) $1: 1,1: 2,1: 3,1: 4$ and $1: 5$ shows $42.55 \%, 46.93 \%, 50.26 \%$, $55.41 \%, 60.12 \%$ drug permeates at 15 minutes and at 45 minutes $78.14 \%, 8.53 \%, 92.23 \%, 95.22 \%, 98.25 \%$ drug permeates, respectively. In same process complex of Sertraline $\mathrm{HCl}$ with

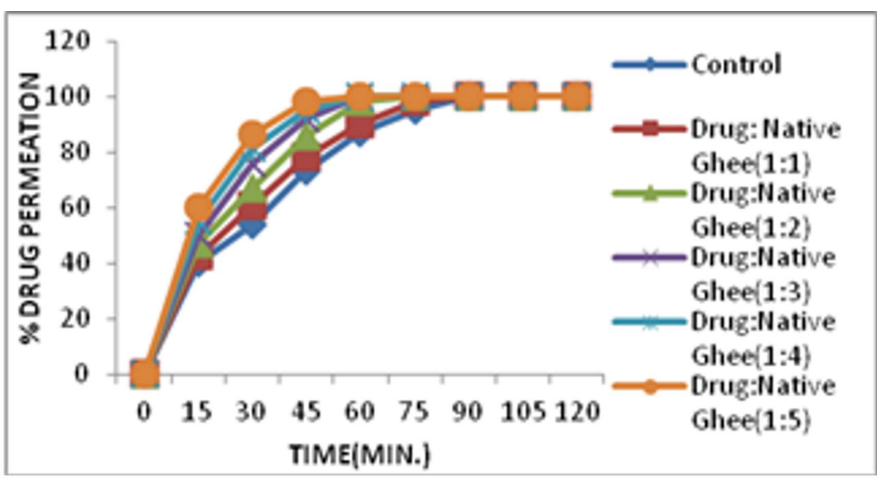

Figure 4. Permeation Study of Drug: Native Cow Ghee

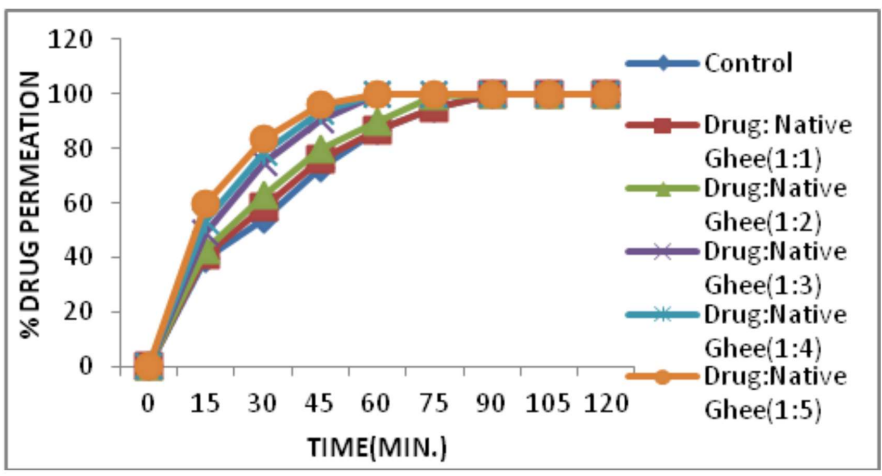

Figure 5.: Permeation Study of Drug: Oxidized Cow Ghee oxidized ghee (figure5) was found that at 15 minutes in $1: 1,1: 2,1: 3,1: 4$ and $1: 5,40.83 \%, 42.58 \%, 48.95 \%, 53.56 \%$, $59.87 \%$ percent drug permeates respectively. And $72.99 \%$, $76.25 \%, 79.89 \%, 90.15 \%, 93.87 \%, 96.16 \%$ drug permeates at 45 minutes. This means while increasing the amount of ghee in complex ratio, $\%$ drug permeation increases.

\section{Differential scanning calorimetry (DSC)}

The native ghee exhibited endotherms at $11.28^{\circ} \mathrm{C}$ and $44.93^{\circ} \mathrm{C}$ followed by slanting line up to $300^{\circ} \mathrm{C}$. In case of oxidized ghee, the peaks were sharp as compare to native ghee indicating probably purified material at $13.45^{\circ} \mathrm{C}$ and $45.04^{\circ} \mathrm{C}$. The slanting line of native ghee was here almost straight up to $200^{\circ} \mathrm{C}$ and thereafter slightly decrease up to $300^{\circ} \mathrm{C}$ probably indicating a product free of some residual material which was there in native ghee. Sertraline $\mathrm{HCl}$ having a melting point of 243 when complex with native ghee it shifted to 249.61 and with oxidized ghee it gave a sharp peak at $222^{\circ} \mathrm{C}$ and broad peaks at $242.93^{\circ} \mathrm{C}$ and $269^{\circ} \mathrm{C}$.

\section{Discussion}

Ghee contain sufficient amount of saturated fats and cholesterol and enhance risk factor for cardiovascular disease. Therefore oxidizing ghee by heating it in an electric stainless steel oven at $120^{\circ} \mathrm{C}$ for 50 hours 17 times the concentration of oxysterol in the preparation. Oxidized ghee contain enhanced free cholesterol ester fraction in mucosal cells, indicating that esterification process of cholesterol in the intestine is inhibited by ghee lipids (formed in oxidized ghee). Therefore in present investigation, ghee has been oxidized and used further for research work with the view the oxidized ghee can used as pharmaceutical aid for preparation of formulations.

Complexation in pharmaceuticals has shown the way to enhance drug stability and thereby bioavailability of many low soluble drugs. Many researchers formulated various types of complexes reference of which cyclodextrin complex is the most common one. Sertraline $\mathrm{HCl}$ drugs used for CNS activity exhibits low bioavailability hence we have attempted to make a Sertraline ghee complex which would probably enhance drug permeability and thereby bioavailability. Drug ghee complexes prepared at various ratios were evaluated for drug dissolution and permeation studies. Formulation containing higher percentage of ghee exhibited lower drug release as compared to lower drug ghee complexes. The emulsified drug ghee complexes permeated with ease across the intestinal epithelium barrier. On the other hand, the permeation was enhanced as the amount of ghee fractions increased as there is a possibility 


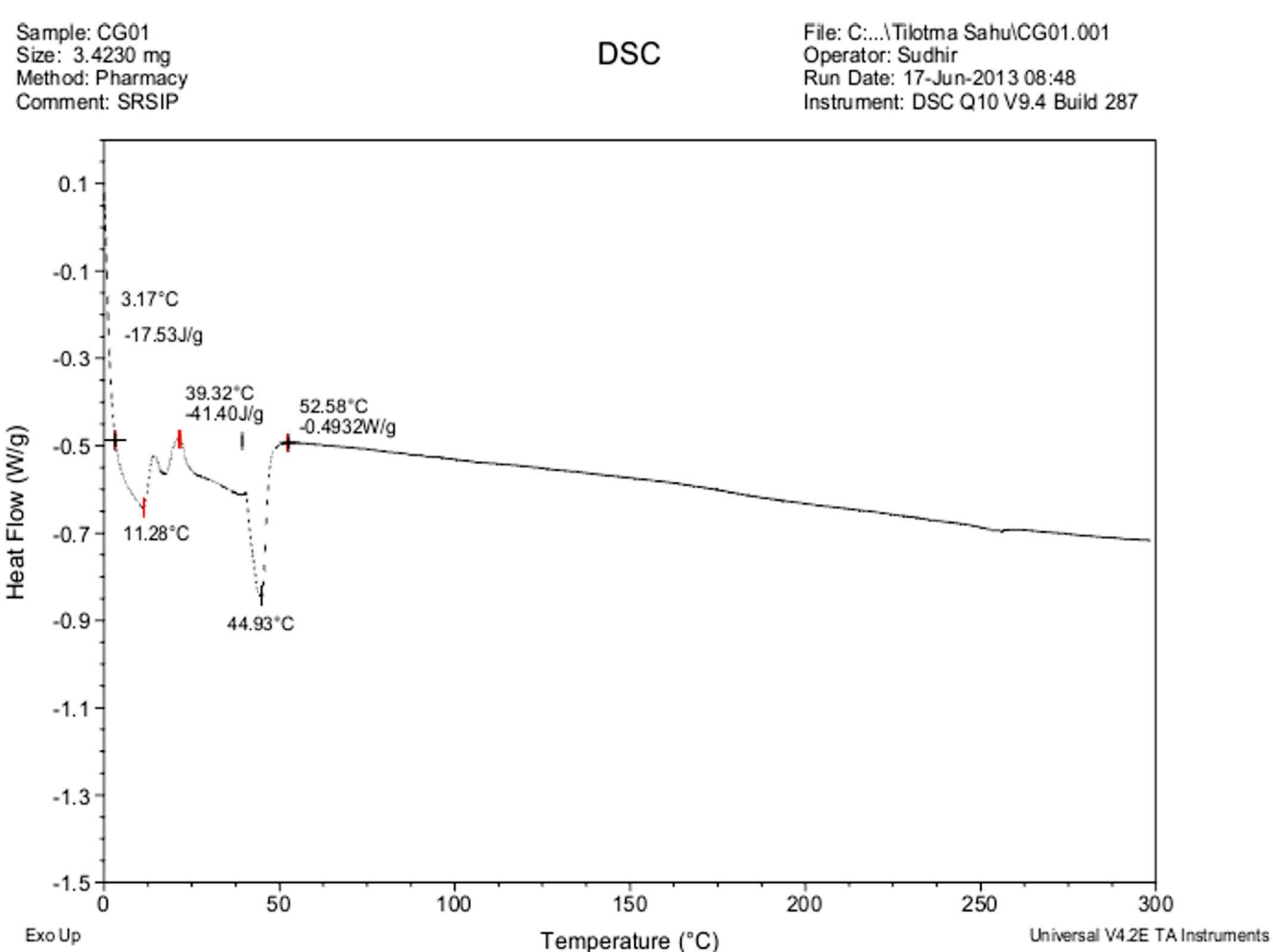

Figure 6. DSC of Native Cow Ghee

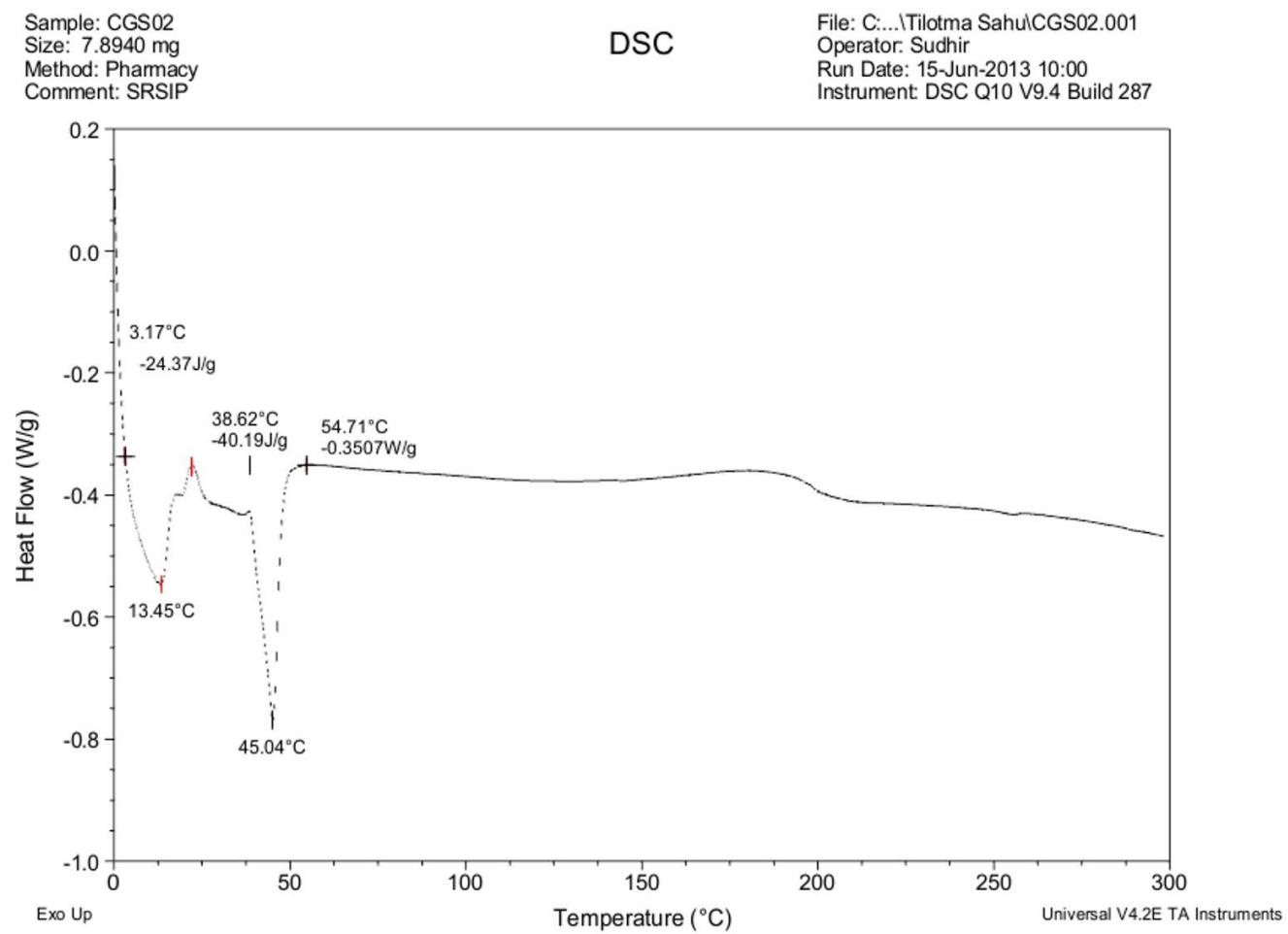

Figure 6a. DSC of Oxidized Ghee

that the drug complexes would been further entrapped in higher ghee fractions. Thus the hypothesis of enhancing drug permeability across the epithelial membrane was achieved but still needs for the evaluation for more systematic approaches.

\section{Conclusion}

From all these studies we can conclude that by preparing drug ghee complex we can sustain the release of drug in different dosage form like tablet or capsule dosage form. 


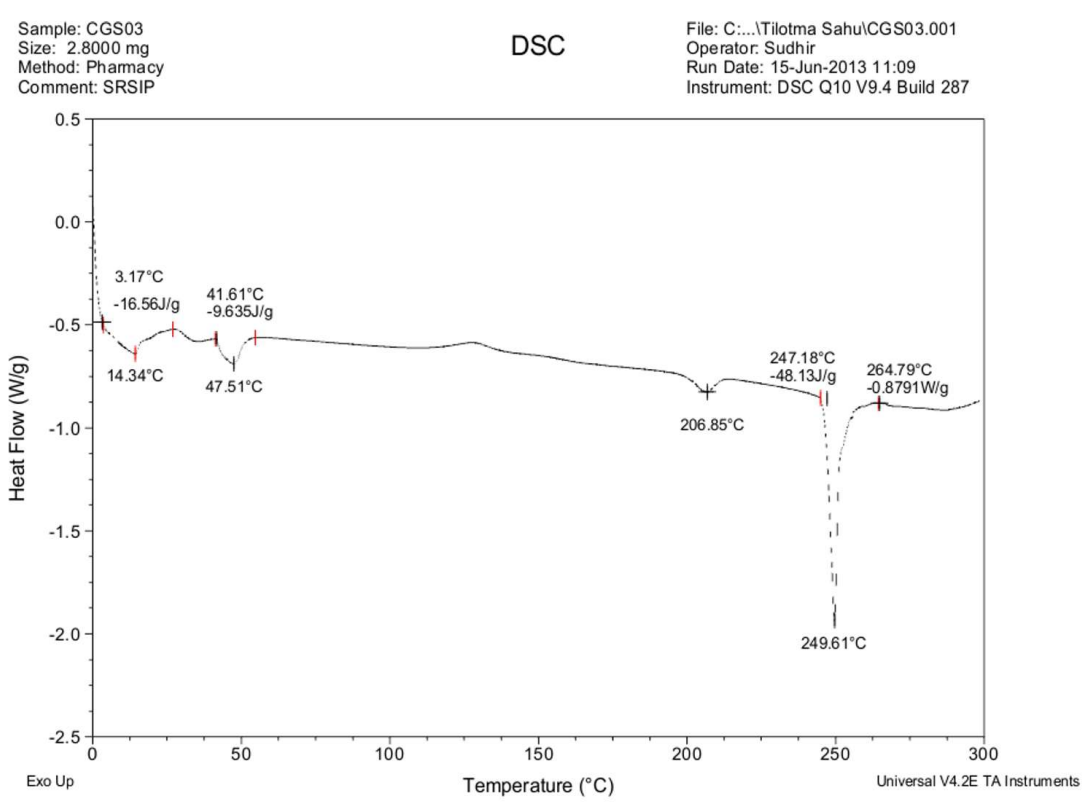

Figure 6b. DSC of Sertraline HCl: Cow Ghee

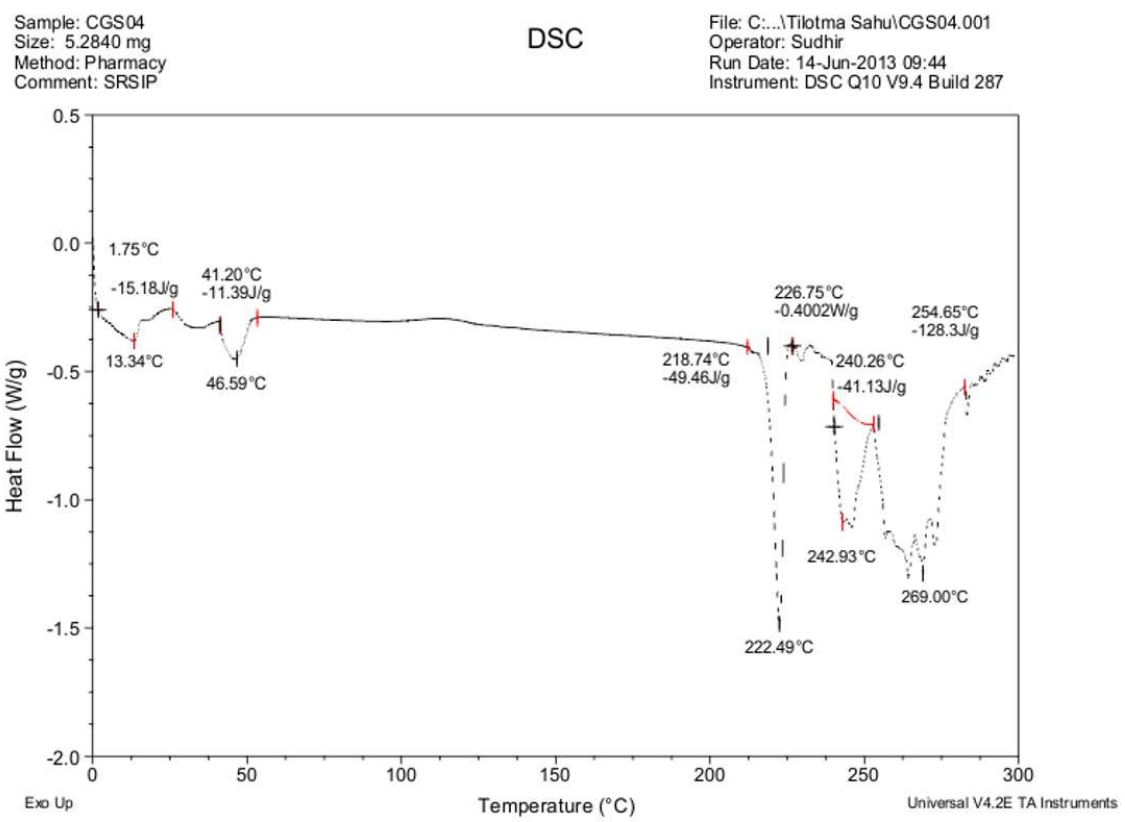

Figure 6c. DSC of Srtraline $\mathrm{HCl}$ : Oxidized Ghee Complex (1:1)

The preliminary study of drug ghee complex of Sertraline $\mathrm{HCl}$ exhibited different physicochemical characteristics thereby interpreting the formation of complexes. Further the improved permeation supports their formulation steps and hence the drug ghee complexes can be used for improvement of drug therapeutics.

\section{Conflicts of interest}

The authors report no conflict of interest between themselves.

\section{References}

Censi R, Martino PD. 2015. Polymorph Impact on the
Bioavailability and Stability of Poorly Soluble Drugs. Molecules 20:18759-18776.

Kansara H, Panola R, Mishra A. 2015. Techniques used to Enhance Bioavailability of BCS Class II Drugs: A Review. International Journal of Drug Development \& Research 7(1): 82-93.

Salih OS. 2015. Study The Sustain Release Effect of Different Polymers Used In The Formulation of Aspirin-Rosuvastatin Tablets. International Journal of Pharmacy and Pharmaceutical Sciences 7(12):166-172. 
Kotamkar AA, Sakarkar SN. 2014. Effect on In Vitro Permeation of Carbamazepine in Existence of Various Additives in Ussing Chamber. International Journal of Pharmaceutical and Phytopharmacological Research 3(4):264-267.

Hussein OA, Ghorab MM, Mostafa DM, Ghoneim DM. 2014. Self-Nanoemulsifying Drug Delivery System For Sertraline Hydrochloride: Design, Preparation And Characterization. International Journal of Pharmacy and Pharmaceutical Sciences, 6(9):589-595.

Bawankar RD, Sakarkar DM, Dorle AK. 2016. Comparative Prediction of Plasma Concentration, Blood Brain Barrier Penetration, Intestinal Absorption And Skin Diffusion of Diclofenac Sodium and its Complex with Cow's Ghee in Swiss Albino Mice. International Journal of Pharmaceutical \& Biological Archives 7(2):14-21.

Nirmala KS, Manjula BS, Sajahananda H. 2016. Effect of Two Types of Dietary Ghee on Serum Lipid Levels in Rats. Journal of Evolution of Medical and Dental Sciences 5(49):3240-3244.

Ratnia R, Yadav V, Kumar A. 2015. Method Development and Its Validation for Estimation of Sertraline Hydrochloride by Using UV Spectroscopy. International Journal of Pharma Research and Health Sciences 3(2):616-620.

Kale VV, kasliwal RH, Avari JG. 2007. Attempt to Design Continuous Dissolution-Absorption System Using Everted Intestine Segment for In Vitro Absorption Studies of Slow Drug Release Formulations. Dissolution Technologies 3136.

Narkhede SP, Raval HV, Bendale AR, Jadhav AG, Vdyasagar G. 2011.; A Discriminating UV-Spectrophotometric Method for In-Vitro Dissolution Study of Sertraline Hydrochloride in Tablet Dosage Form. Journal of Chemical and Pharmaceutical Research 3(6):361-368.

Warrier D, Zagade A, Shaikh A, Pawar Y, Kumbhar S. 2012. An In-Vitro Evaluation For The Effect of B- Cyclodextrin And Pvp-K 30 on Drug Release Pattern of Sertraline Hydrochloride; International Journal of Pharmaceutical And Chemical Sciences 1(1):407-413.

Matam VK, Kari S, Belur RL. 2000. Hypocholesterolemic Effect of Anhydrous Milk Fat Ghee is Mediated by Increasing The Secretion of Biliary Lipids. Journal of Nutrition Biochemistry 11:69-75. 